\title{
Experimental Study on Thermal Interaction of Ethanol Jets in High Temperature Fluorinert*
}

\author{
Rongyuan SA** and Minoru TAKAHASHI*** \\ ** Department of Nuclear Engineering, Tokyo Institute of Technology \\ 2-12-1 N1-18, O-okayama, Meguro-ku, Tokyo, 152-8550, Japan \\ E-mail: sa.r.aa@m.titech.ac.jp \\ *** Research Laboratory for Nuclear Reactors, Tokyo Institute of Technology \\ 2-12-1 N1-18, O-okayama, Meguro-ku, Tokyo, 152-8550, Japan
}

\begin{abstract}
As a fundamental study for the direct contact heat exchange which was employed for in-vessel heat exchange in the $\mathrm{Pb}$-Bi-cooled direct contact boiling water small fast reactor (PBWFR) and for the steam generator tube rupture (SGTR) accident in lead alloy-cooled fast reactor (LFR), ethanol jet was injected into high temperature fluorinert (FC-3283) as a simulation experiment in order to investigate the jet boiling phenomena just after volatile water contacting with the high temperature continuous lead alloy liquid. Two series of tests (no-boiling and boiling) were initiated to evaluate the ethanol vapor volume which generated around the ethanol jet. From synchronized temperature measurement around ethanol jet, the overview of the boiling behavior showed that jet boiling occurred at bottom part of jet first and developed to the upper part within very narrow area around jet.
\end{abstract}

Key words: Lead Alloy-Cooled Fast Reactor, Pb-Bi, Direct Contact, Boiling, Small Fast Reactor, Heat Exchanger, Jet, Image Processing

\section{Introduction}

Direct contact heat exchange is an efficient method for heat exchanger because of simpler design, higher heat transfer coefficient and no corrosion problem without metallic heat transfer surfaces. It has been utilized in nuclear industry including safety analyses of steam generator tube rupture (SGTR) accident in lead-cooled fast reactors (LFR) [1] and in-vessel heat exchange for Pb-Bi-cooled Direct Contact Boiling Water Small Fast Reactor (PBWFR) [2].

Some studies about the direct contact heat exchange were carried out. Takahashi et al. [3-5] and Yamada et al. [6] conducted a water-LBE (lead-bismuth eutectic) direct contact boiling experiment and an Ar gas-LBE two-phase flow experiment. The major purposes were to investigate the two-phase flow characteristics to evaluate the steam lift performance and heat transfer rate in the direct contact boiling flow. However, since the difficulty in observation in opaque invisible melt, the boiling phenomena was not been clarified enough, especially near the initial contact area where water was jetted into LBE. The local phenomena, such as jet appearance, vapor generation rate and temperature distribution around jet, must be clarified to develop a sufficient correlation for design water injector and performance calculations of upstream two-phase flow.

Sibamoto et al. $[7,8]$ visualized and measured transient intrusion of a subcooled water 
jet into a molten LBE using a high-frame-rate neutron radiography (NRG) technique. However, it is difficult to evaluate the vapor volume in the cavity directly from neutron radiography images.

On the other hand, direct contact heat exchange using transparent immiscible binary, such as water/organic-fluid, has been studied extensively. Sideman et al [9] investigated the heat transfer characteristics on butane or pentane drops/water. Tadrist et al. [10] investigated the heat transfer characteristics on n-pentane/water counter-current system. Shimaoka and Mori [11] experimentally investigated the evaporating heat transfer of n-pentane/n-hexane mixture heated by water. However, these works focused on the evaporation of the liquid droplets in another liquid flow. They were significantly different from the liquid jet boiling conditions which allowed the existence of the liquid-liquid interface with large area.

Since the complicated nature of the current problem and the lack of data in the literature, the preliminary jet boiling experiments were performed by using ethanol as jet, and transparent FC-3283 as hot liquid to investigate the boiling jet appearance, vapor generation volume and temperature distribution around jet.

\section{Experimental apparatus and procedure}

Fig. 1 shows a schematic diagram of the experimental apparatus which mainly consists of an ethanol vessel, a straight injection nozzle and a SS type of fluorinert FC-3283 vessel with viewing windows so that high speed imaging of the injection process is possible.

The ethanol temperature and pressure are controlled by the heater around the ethanol vessel and high pressure $\mathrm{N}_{2}$ gas, respectively. A solenoid valve which is connected downstream of ethanol vessel is used to open and close the injection nozzle (0.5 mm I.D.).

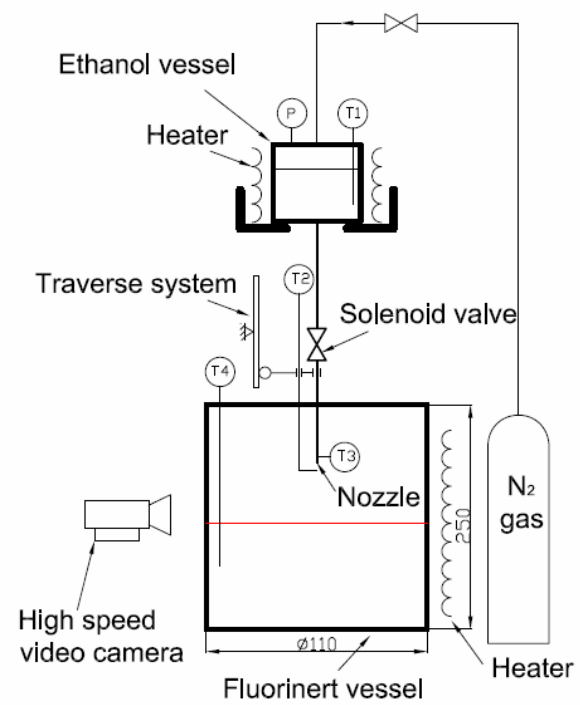

Fig. 1 Schematic experimental apparatus

FC-3283 is filled into a stainless steel vessel (Ø110mm I.D., 250mm high) with free surface $80 \mathrm{~mm}$ above the bottom. Two windows with transparent polycarbonate plates are used to observe the behavior of injection. A high speed camera with a powerful steady state light source positioned at the opposite windows is used for imaging at rates up to 1000 frames per second with the resolution of $256 \times 240$ pixels. A $5 \mathrm{~V}$ pulse is used to trigger the camera and a solid state relay switch which powers up the solenoid valves, hence synchronizing the data acquisition with the image acquisition. Because of the mechanical character of valve spring and pressure gradients, the period of injection is a little longer than the trigger pulse width. The relationship between the jet velocity and the ethanol tank pressure has been established through calibration tests. The FC-3283 temperature is 
controlled by the heater around the vessel.

Two thermocouples with rapid response character are fabricated in this test (see Fig. 2): the first one (T3) which is made by $\varnothing 0.1 \mathrm{~mm}$ alumel and chromel wires is inserted inside the nozzle and located near the outlet of nozzle to measure the initial temperature of jet, the second one (T2) which is positioned below nozzle using unsheathed alumel-chromel thermocouple with spot welded $\varnothing 0.1 \mathrm{~mm}$ alumel and chromel wires on the tip for rapid measurement of the downstream fluid temperature. In order to keep the relative distance between nozzle outlet and T2 precisely and reduce the heat input to ethanol jet before injection, a traverse system is employed to lift the nozzle before the injection. The temperature data is acquired and stored through data-acquisition hardware at a rate of 1000 samples per second.

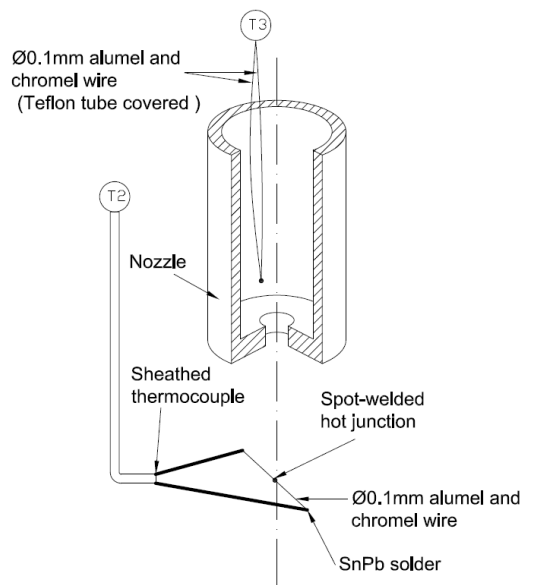

Fig. 2 Rapid response thermocouple assembly

In order to investigate the direct contact heat transfer of water jet in LBE, a simulating test might be desirable to conduct the investigation at considerably low temperature with different fluids pairs, such as butane \& pentane drops / water [9], Isopentane \& cyclopentane / water [12], n-pentane / water [13,14]. Buongiorno et al. [15] pointed out that "If fluids other than water / LBE are selected as stimulants of water / LBE, the experimental results must be correlated and interpreted in terms of dimensionless numbers to allow a meaningful conversion to different fluids and / or thermal-hydraulic conditions." $\mathrm{He}$ recommend that Biot number

$$
B_{i} \propto \frac{k_{c o n}^{0.2} \rho_{c o n}^{0.2} c_{p, c o n}^{0.8} \sigma_{c o n}^{0.6}}{k_{\text {dis }} g^{0.2}\left(1-\frac{\rho_{\text {dis }}}{\rho_{\text {con }}}\right)} \approx \frac{k_{c o n}^{0.2} \rho_{c o n}^{0.2} n_{p, c o n}^{0.8} \sigma_{c o n}^{0.6}}{k_{\text {dis }} g^{0.2}} \text { (i.e. the ratio of the }
$$

dispersed to continuum phase thermal resistance) could be used in selecting the simulating fluids so that the $B i$ number is kept approximately the same as the water / LBE pair. In Table 1, the previous research works are summarized as Pair A, In the present experiments, fluorinert (FC-3283) is used as the simulant liquid metal material because of its alcohols-insoluble, transparent, colorless and higher density character. The volatile liquid is selected as ethanol since its boiling temperature $(350 \mathrm{~K})$ is lower. The corresponding thermal characteristics are listed as a Pair B in Table 1. The most important is that this simulant pair owes a 1647 of Bi number which is closed to the real pair. At present, the authors consider that it is the best simulant pairs to simulate the water / LBE direct contact heat transfer. 
Table 1 Comparison of selected simulants liquids

\begin{tabular}{|c|c|c|c|}
\hline & $\begin{array}{l}\text { Continuum phase } \\
\text { liquid }\end{array}$ & Dispersed phase liquid & Bi number \\
\hline Real pairs & $\begin{array}{l}\operatorname{LBE}\left(310-460^{\circ} \mathrm{C}\right) \\
k_{\text {con }}=10.73 \mathrm{~W} /(\mathrm{mK}) \\
\rho_{\text {con }}=10437 \mathrm{~kg} / \mathrm{m}^{3} \\
c_{p, c o n}=147 \mathrm{~J} /(\mathrm{kgK}) \\
\sigma_{c o n}=0.404 \mathrm{~N} / \mathrm{m}\end{array}$ & $\begin{array}{l}\text { Water/steam } \quad\left(220-296^{\circ} \mathrm{C} \text {, }\right. \\
7 \mathrm{MPa}) \\
k_{\text {disv }}=0.0629 \mathrm{~W} /(\mathrm{mK})\end{array}$ & $\sim 3240$ \\
\hline $\begin{array}{ll}\text { Pair } & \text { A } \\
{[1-4]} & \end{array}$ & $\begin{array}{l}\text { Water }\left(20-60^{\circ} \mathrm{C}\right) \\
k_{\text {con }}=0.5984 \mathrm{~W} /(\mathrm{mK}) \\
\rho_{\text {con }}=998 \mathrm{~kg} / \mathrm{m}^{3} \\
c_{p, c o n}=4184 \mathrm{~J} /(\mathrm{kgK}) \\
\sigma_{c o n}=0.073 \mathrm{~N} / \mathrm{m}\end{array}$ & $\begin{array}{l}\text { Butane, pentane, n-pentane, } \\
\text { Isopentane } \quad\left(20-50^{\circ} \mathrm{C} \text {, }\right. \\
0.1 \mathrm{MPa}) \\
k_{\text {disv }}=0.0141-0.0153 \mathrm{~W} / \\
(\mathrm{mK})\end{array}$ & $\sim 24100-26500$ \\
\hline Pair B & $\begin{array}{l}\text { FC-3283(100 C) } \\
k_{\text {con }}=0.0594 \mathrm{~W} /(\mathrm{mK}) \\
\rho_{\text {con }}=1632.5 \mathrm{~kg} / \mathrm{m}^{3} \\
c_{p, c o n}=1169.4 \mathrm{~J} /(\mathrm{kgK}) \\
\sigma_{c o n}=0.015 \mathrm{~N} / \mathrm{m}\end{array}$ & $\begin{array}{l}\text { Ethanol }\left(78^{\circ} \mathrm{C}, 0.1 \mathrm{MPa}\right) \\
k_{\text {disv }}=0.022 \mathrm{~W} /(\mathrm{mK})\end{array}$ & $\sim 1647$ \\
\hline
\end{tabular}

Two kinds of experiment were performed. "Experiment 1" was performed in order to compare the configuration of the ethanol jet with or without boiling phenomena. "Experiment 2" was performed in order to measure the temperature distribution around ethanol jet with boiling.

\subsection{Experiment 1}

In order to observe the configuration of the jet boiling, "experiment 1 " was performed. Ethanol and FC-3283 temperatures were controlled to achieve two series of tests: no boiling and boiling jet. During the tests, thermocouple T2 was removed in order to eliminate the influence on the integrity of the jet. The experimental conditions are shown in Table 2.

Table 2 Experimental 1 conditions

\begin{tabular}{|c|l|l|l|l|}
\hline Fluid/parameters & Run 1 & Run 2 & Run 3 & Run 4 \\
\hline FC-3283 (Pool liquid) & & & & \\
$\quad$ Initial temperature (K) & 290 & 390 & 390 & 390 \\
& & & & \\
Ethanol (Jet liquid ) & & & & \\
Nozzle diameter (mm) & 0.5 & 0.5 & 0.5 & 0.5 \\
Initial temperature (K) & 290 & 320 & 330 & 340 \\
Mass flow rate (g/s) & $\sim 0.12$ & $\sim 0.12$ & $\sim 0.12$ & $\sim 0.12$ \\
Injection period (s) & $\sim 1.1$ & $\sim 1.1$ & $\sim 1.1$ & $\sim 1.1$ \\
\hline
\end{tabular}

\subsection{Experiment 2}

In order to define the quantitatively the local fractions of ethanol, ethanol vapor and FC-3283 as well as to obtain the phase boundaries, "experiment 2" was performed. As a first step, the local temperature distribution around jet was obtained through thermocouple T2. Sixteen series of tests which T2 located at different positions (shown in Fig. 3) were achieved. 


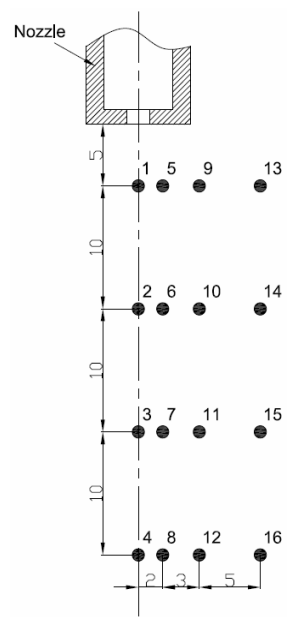

Fig. 3 Thermocouple T2 locations (unit:mm)

\section{Experimental results and discussion}

\subsection{Overview of the non-boiling and boiling behaviors of jet}

Fig.4 shows consecutive images of an ethanol jet injected into a FC-3283 pool for four tests conducted for different jet and pool temperatures. When the desired temperature achieved, the nozzle outlet was vertically immersed into the FC-3283 pool at the level $1 \mathrm{~cm}$ below free surface in order to eliminate the air entrainment during the jet injection. The time of $0 \mathrm{~ms}$ was set when the jet front tip started to penetrate into the pool.

For Run 1, a non-boiling isothermal test was achieved when both temperatures of ethanol jet and FC-3283 pool were 290K. The ethanol jet showed a smooth cylinder type first when it was injected into FC-3283. At about $30 \mathrm{~ms}$, the jet was divided into two regions: (1) a developing region also called the potential core and (2) a fully developed turbulent region. Large-scale structures at the end of the potential core were clearly observed just before the jet broke up into a random, turbulent flow. The end of potential core occurred at about $1-1.5 \mathrm{~cm}$ apart from the nozzle. Finally, all the ethanol droplets lifted up because of the buoyancy effect of the lighter ethanol.

For Run 2, FC-3283 and ethanol temperatures were $390 \mathrm{~K}$ and $320 \mathrm{~K}$, respectively. Turbulent flow with black background was observed at $50 \mathrm{~ms}$. Although it is difficult to distinguish the three phase (FC-3283, ethanol and ethanol vapor) at present test, we can proposed that direct contact heat exchange occurred and ethanol tiny vapor and droplet mixed together to generate those turbulent flow. It needed longer time to generate visible large vapor because the relative large temperature difference between ethanol and FC-3283. At $\mathrm{t}=250 \mathrm{~ms}$, visible vapor was observed around the jet, especially at the bottom part. After that, the vapor grew and lifted up due to the buoyancy effect. The upper part of jet also vaporized during that period.

When we increased the ethanol jet temperature to $330 \mathrm{~K}$ (see Run3), the pattern was the same with the $320 \mathrm{~K}$ case before $100 \mathrm{~ms}$. However, visible large vapor quickly appeared $(\mathrm{t}=125 \mathrm{~ms})$. When we increased the ethanol jet temperature to $340 \mathrm{~K}$ which was almost saturated temperature of ethanol (see Run4), the visible vapor suddenly grew around the jet (see $\mathrm{t}=40 \mathrm{~ms}$ ). The turbulent flow was not so significant because the quick vaporization effect, and this boiling effect also shortened the penetration depth of the jet. 


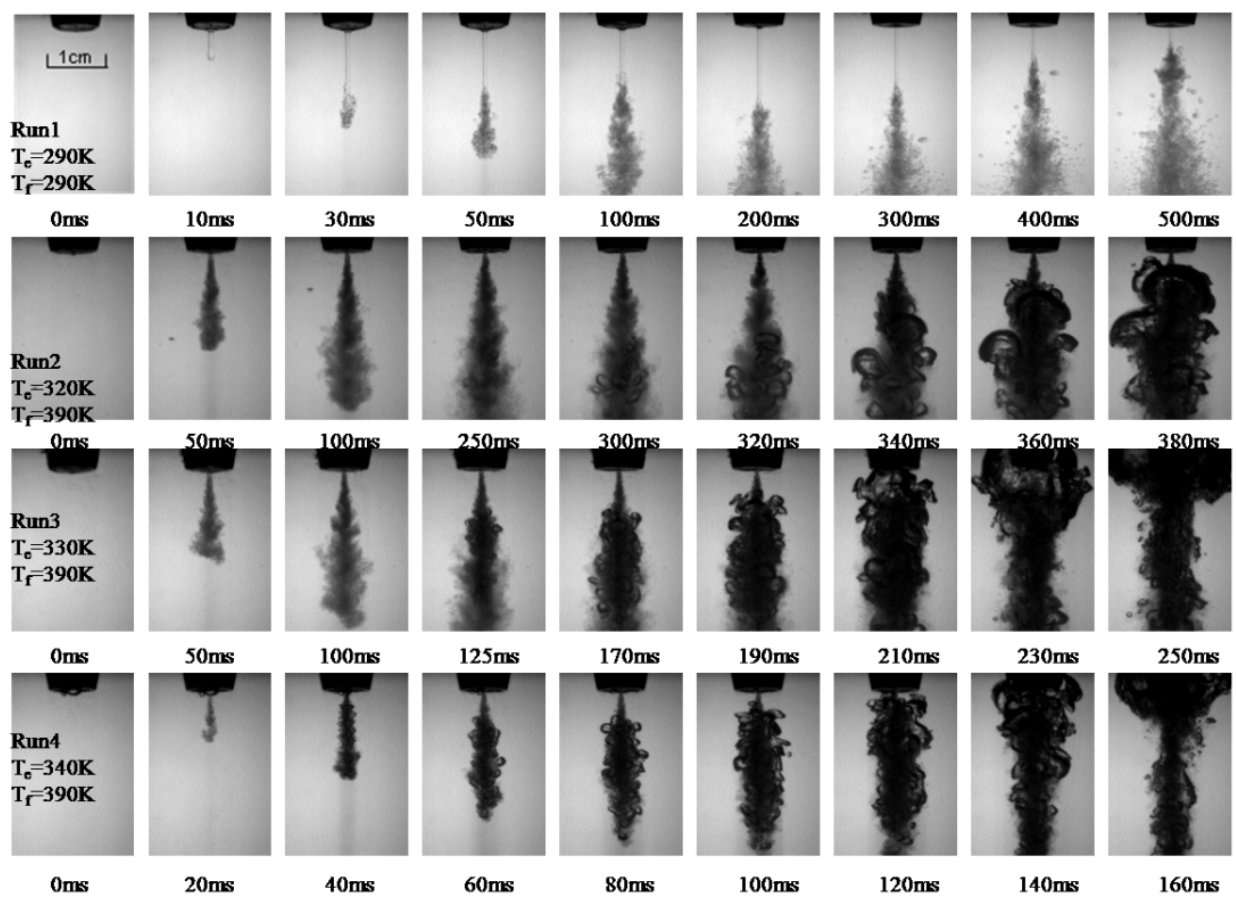

Fig. 4 Visulization of no-boiling and boiling behavior of ethanol jet injected into FC-3283

\subsection{Ethanol vapor volume for boiling tests}

Because of the complicate behavior of jet boiling, the original images could not clearly show the detail, and therefore it was necessary to extract heat transfer information from the gray-level digital images. We defined the black part of image where the direct boiling occurred as "mix zone". An image processing code was developed to accurately calculate the mixing zone volume and thereby deduced the vapor volume quantitatively by further analysis. Those images were binarized to extract the border of the mixing zone, and to calculate mixing zone volumes depending on the cylinder shape assumption:

$V_{m}=\sum_{i}^{240} V_{i}=\sum_{i}^{240} k^{3} \frac{\pi x_{i}^{2}}{4}$

where $V_{m}$ is the total mix zone volume, $V_{i}$ is the mix zone volume at $i$ line of pixel, $k$ is the ratio of actual length and pixel, and $x_{i}$ is the No. of pixel inside of the mixing zone border at $i$ line.

Since the ethanol jet was injected into stagnant FC-3283 liquid through a 0.5mm I.D. injection nozzle with $0 \circ$ of spray degree, the initial shape of ethanol jet could reasonably be assumed as a cylinder column, the cylinder shape assumption for the mixing zone is valid when boiling occurred symmetrically. The only error for establishing the volume of mixing zone came from the binary image processing (the uncertainty of boundary line length $x_{i}$ ).

Error $=\frac{\left|\delta V_{m}\right|}{V_{m}}=\frac{\left|\sum_{i}^{240} \delta V_{i}\right|}{\sum_{i}^{240} V_{i}}=\frac{\left|\sum_{i}^{240} \delta\left(k^{3} \frac{\pi x_{i}^{2}}{4}\right)\right|}{\sum_{i}^{240} k^{3} \frac{\pi x_{i}^{2}}{4}}=\frac{\left|\sum_{i}^{240} \delta\left(x_{i}^{2}\right)\right|}{\sum_{i}^{240} x_{i}^{2}}=\frac{\left|\sum_{i}^{240} 2 x_{i} \Delta x_{i}\right|}{\sum_{i}^{240} x_{i}^{2}}$

The uncertainty of the boundary line is limited to 2 pixels. Since the spatial resolution is estimated to be $0.142 \mathrm{~mm} / \mathrm{pixel}$, relative error will less than $10 \%$ when vapor volume less than $5 \mathrm{~mL}$.

Figs. 5 (a), (b) and (c) show typical original image, binary image and volume calculation illustration, respectively. 


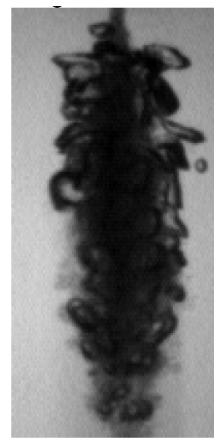

(a)

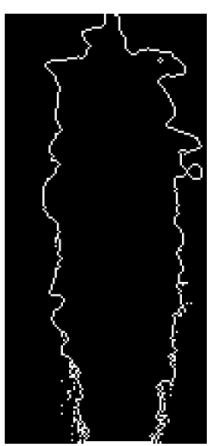

(b)

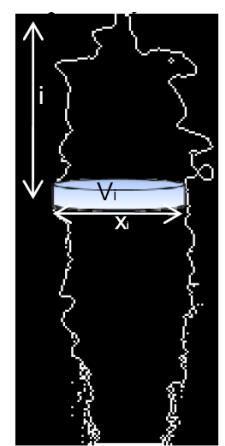

(c)

Fig. 5 (a) Original image (b) Binary image (c) Schematic illustration of mix zone volume calculation

Fig. 6 shows the mixing zone volume for four runs. Vacant and solid circular symbols indicate the results at the time when the vapor was observed visibly and at the time when vapor started splashing out of view field, respectively. For Run 1, the mixing zone volume did not change so much, since it just contained the ethanol droplets and FC-3283 liquid because of the turbulent flow and jet breakup without vapor generation. For the other three boiling tests (Run 2,3,4), it is clearly shown that there were large amount of generated volume, since direct contact boiling occurred. The earliest vaporization time started in the highest jet temperature case (Run 4). However, since the vaporization was quick when the temperature difference was small (Run 4), the jet was shattered into vapor cloud in a short time, which induced the shallow injection depth.

Because it was difficult to determine the ethanol vapor volume in the mixing zone directly from original images, a simple method was employed to determine this volume indirectly by subtracting the initial volume value (when visible vapor was observed ) for each boiling test.

Fig. 7 shows the ethanol vapor volumes for different jet temperatures. We set the $t=0 \mathrm{~ms}$ when visible vapor was observed. For Run 4, the vapor volume was a little larger than the others (especially before $\mathrm{t}=80 \mathrm{~ms}$ ) because of the higher initial temperature of jet which induced quick vaporization when it contacted with hot FC-3283. However, because of the buoyancy effect of vapor, the downstream vapor lifted up (after $\mathrm{t}=80 \mathrm{~ms}$ ), which let the vapor volume of Run 2 and 3 larger.

\subsection{Temperature distribution around ethanol jet}

After Experiment 1 where the boiling phenomena of jet periphery had already been observed, Experiment 2 was achieved in order to identify the properties of fluid inside of the jet core. Fig. 8 shows the temperature distribution around ethanol jet at different points (see detail in Fig. 3). During the test, the jet and pool initial temperatures were control at $340 \mathrm{~K}$ and $390 \mathrm{~K}$, respectively.

Series 1 tests (point 1,2,3,4) where the thermocouple T2 was located downstream of nozzle centerline step by step were achieved first. Temperature of point 1 suddenly fell to about $340 \mathrm{~K}$ because T2 contacted with liquid ethanol and the jet was in a liquid phase up to the point $2(15 \mathrm{~mm}$ below form the nozzle). When the jet penetrated continually, the local temperature at the point 3 shows higher than the boiling temperature of ethanol ( $\left.\mathrm{T}_{\text {boiling }}=350 \mathrm{~K}\right)$. It means that although it was difficult to identify the kind of fluid in contact with the thermocouple (cooled FC-3283 or ethanol vapor), it could be clearly mentioned that no liquid ethanol exist below this point, and the ethanol jet had already broken up or vaporized because of the turbulent flow and direct contact boiling effect. This phenomena can also be proved by means of visualization test (see Fig. 4 Run $4 \mathrm{t}=80 \mathrm{~ms}$ ). 


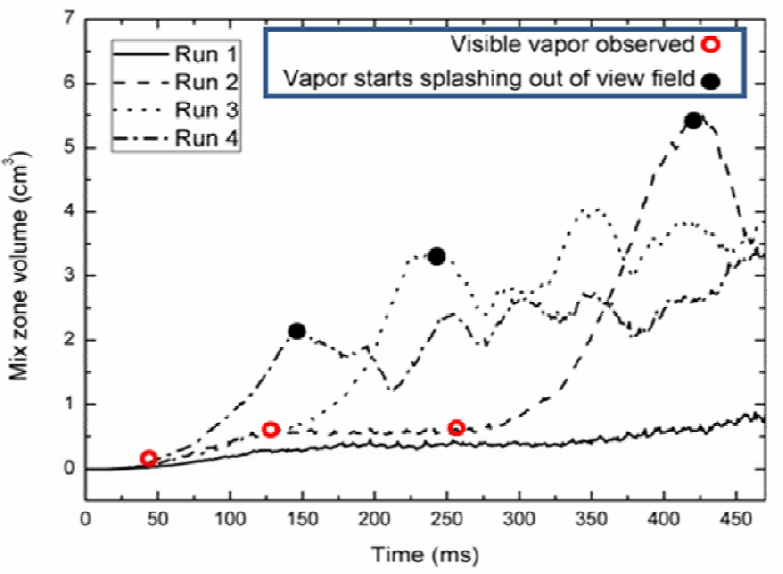

Fig. 6 Mixing zone volumes

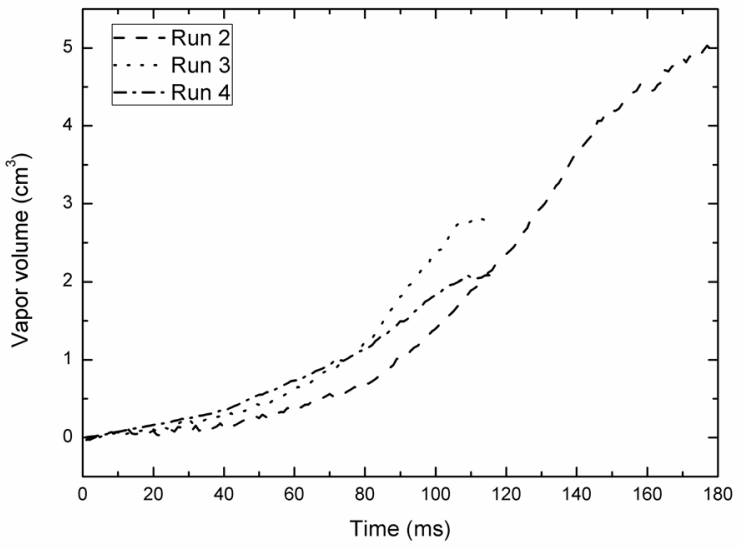

Fig. 7 Ethanol vapor volumes for boiling tests

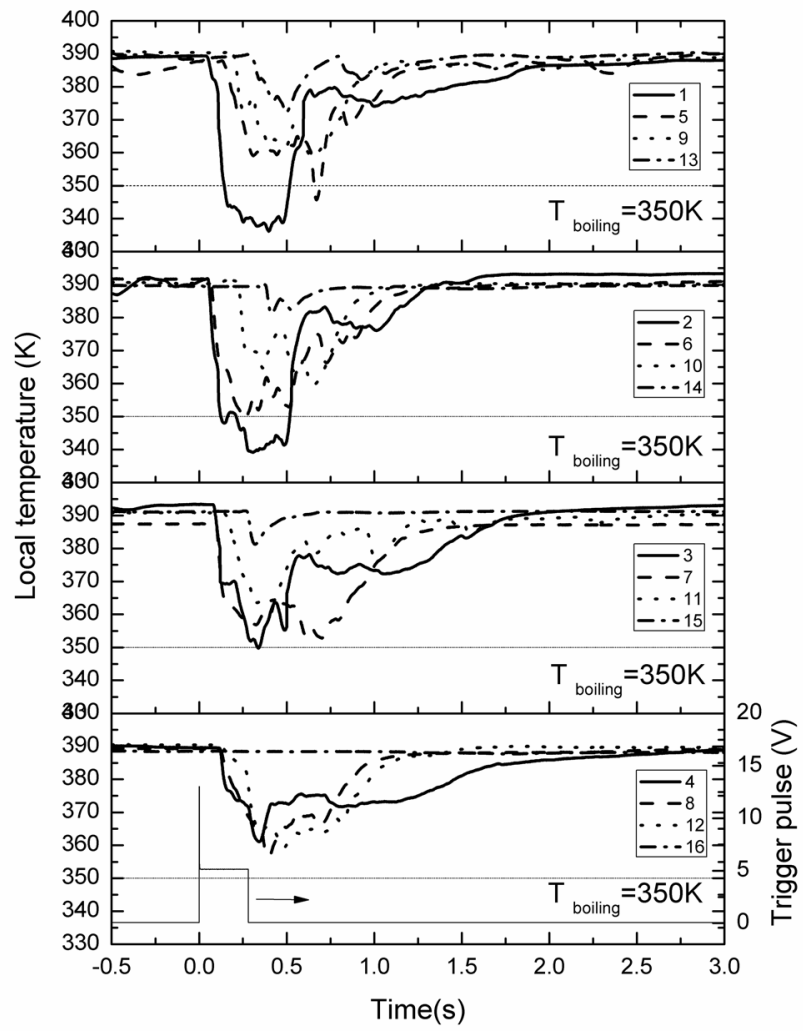

Fig. 8 Temperature distribution around ethanol jet at different points 
Two series of tests were achieved beside the centerline of jet, i.e., series 2 tests (point $5,6,7,8)$ which were for $2 \mathrm{~mm}$ apart from the centerline and series 3 tests (point 9, 10, 11, 12) which were for $5 \mathrm{~mm}$ apart from the centerline. The two series of tests showed that no liquid ethanol existed and the jet mainly contained the ethanol vapor or cooled FC-3283 droplets.

It should be noted that the series 4 tests (point 13, 14, 15, 16) which were for $10 \mathrm{~mm}$ apart from the centerline showed minimum change of local temperatures. Especially at the point 16 , no temperature changed at all, which means that the direct boiling was limited in very narrow area around the ethanol jet.

For each series of test in Experiment 2, three times of test was started, all the test curves show the similar tendency, and the lowest temperature value with in $\pm 6-7 \mathrm{~K}$ could represent a good repeatability of the test results.

Comparison with Run 4 vide-frames in Experiment 1 and temperature distribution in Experiment 2 brought the image of the jet boiling clearly. At $t=20,40$ and $60 \mathrm{~ms}$, the ethanol jet attached to the T1, T2 and T3 continuously. The corresponding temperature decreased to about $340 \mathrm{~K}$ since the liquid ethanol jet core existed in the center line. Since the jet boiling occurred at bottom first, the temperatures at T7 and T6 more quickly decreased compared with T5. From $t=80$ to $120 \mathrm{~ms}$, the jet boiling occurred continuously, mixing zone expanded, and the temperature corresponding to T9, T10 and T11 have the same tendency with those at the T5, T6 and T7.

The further work which have a large visualization area (covered the point 4, 8, 12, 13, 14,15 and 16) is recommended to explain the tendency of T4, 8, 12, 13, 14, 15 and 16.

\section{Conclusions}

Direct contact heat exchange using volatile ethanol injected into high temperature FC-3283 liquid was achieved, ethanol jet boiling phenomena were observed using a high speed camera, and local temperature distributions around jet were obtained by using thermocouples with short response time. The following results were obtained in the present study:

For no boiling case, the ethanol jet exhibited a turbulent flow with about $1 \mathrm{~cm}$ of potential core when it penetrated into the high density FC-3283.

For boiling case, an image processing technique was developed to accurately calculate the mixing zone volume and thereby deduced the generated vapor volume. From synchronized temperature measurement around ethanol jet, the overview of the boiling behavior showed that jet boiling occurred at bottom part of jet first and developed in the upper part of jet within very narrow area around jet.

\section{Acknowledgment}

The author would like to acknowledge the support of Mr. Xie Ning (PhD student in the department of computer science at Tokyo Institute of Technology) in programming the image processing code.

\section{References}

[1]. Li. N, Lead-alloy coolant technology and materials - technology readiness level evaluation, Progress in Nuclear Energy, 50(2-6) (2008), pp. 140-151.

[2]. M. Takahashi, S. Uchida, et al., PbBi-cooled direct contact boiling water small reactor, Progress in Nuclear Energy, 47(1-4) (2005), pp. 190-201.

[3]. M. Takahashi, et al., Study on Pb-Bi-Water direct contact boiling two-phase flow and heat transfer, Progress in Nuclear Energy, 47(1-4)(2005), pp. 569-576. 
[4]. Novitrian, et al., Experimental and Analytical Study of Lead-Bismuth-Water Direct Contact Boiling Two-Phase Flow, Journal of Power and Energy Systems, Special Issue on 14th Int. Conference on Nuclear Engineering(2007), pp. 76-86.

[5]. Novitrian, et al., Boiling Heat Transfer Behavior of Lead-bismuth/steam-water Direct Contact Two-phase Flow, Progress in Nuclear Energy 50(2-6) (2008), pp. 625-630.

[6]. Y. Yamada, et al., Experiment and Numerical Simulation of Bubble Behavior in Argon Gas Injection into Lead-Bismuth Pool, Journal of Power and Energy Systems, Special Issue on 14th Int. Conference on Nuclear Engineering (2007), pp. 87-98.

[7]. Yasuteru Sibamoto, Y.K., Hideo Nakamura, Visualization and Measurement of Subcooled Water Jet Injection into High-Temperature Melt by Using High-Frame-Rate Neutron Radiography. Nuclear Technology139(2) (2002), pp. 205-220.

[8]. Sibamoto, Y., Y. Kukita, and H. Nakamura, Small-scale Experiment on Subcooled Water Jet Injection into Molten Alloy by Using Fluid Temperature-Phase Coupled Measurement and Visualization, Journal of Nuclear Science and Technology 44(8) (2007), pp. 1059-1069.

[9]. S. Sideman and Y. Taitel, Heat Transfer with Change of Phase: Evaporation of Drops in an Immiscible Liquid Medium, Int. J. Heat Mass Transfer, 7, pp. 1273 -1964.

[10]. L. Tadrist, J. Sun, R. Santini, J. Pantaloni, Heat transfer with vaporization of a liquid by direct contact in another immiscible liquid: experimental and numerical study, Trans. ASME Ser. (C) 113 (1991), pp. 705-713.

[11]. H. Shimaoka, Y.H. Mori, Evaporation of single drops of n-pentane/n-hexane mixtures in water, Trans. ASME J. Heat Transfer 114 (1992), pp. 965-971.

[12]. Prakash, C.B. and K.L. Pinder, Direct contact heat transfer between two immiscible liquids during vaporization: Part II: Total evaporation time. The Canadian Journal of Chemical Engineering, 45(4) (1967), pp. 215-220.

[13]. Shimizu, Y. and Y.H. Mori, Evaporation of single liquid drops in an immiscible liquid at elevated pressures: equipment and preliminary results. Experiments in Fluids, 6(2) (1988), pp. $73-79$.

[14]. Siqueiros, J. and O. Bonilla, An experimental study of a three-phase, direct-contact heat exchanger. Applied Thermal Engineering, 1999. 19(5): p. 477-493.

[15]. J. Buongiorno et al., Conceptual design of a lead-bismuth cooled fast reactor with in-vessel direct-contact steam generation, $\mathrm{PhD}$ thesis, Massachusetts institute of technology, (2001). 